\title{
Perfil de tradutores-intérpretes de Libras (TILS) Que atuam no ENSINO SUPERIOR NO BRASIL
}

\author{
PROFILE OF BRAZILIAN SIGN LANGUAGE TRANSLATORS/INTERPRETERS (BSLIS)
}

WORKING IN HIGHER EDUCATION

\author{
Cristina Broglia Feitosa de LACERDA ${ }^{1}$ \\ Taís Margutti do Amaral GURGEL ${ }^{2}$
}

\begin{abstract}
RESUMO: este trabalho traz resultados de uma investigação mais ampla junto a tradutores intérpretes de Língua Brasileira de Sinais (TILS) que atuam no Ensino Superior (ES). Destaca o perfil de profissionais que hoje exercem este trabalho na academia, mostrando um pouco as diversas realidades de diferentes regiões em que atuam, faixa etária, formação, como começaram ou se tornaram TILS, como iniciaram seus trabalhos nas Instituições de Ensino Superior (IES), dentre outras. Nesse contexto, destacam-se principalmente aspectos de suas formações e práticas. A investigação se baseou em entrevistas e os resultados variam bastante, demonstrando que há diferentes perfis e especificidades nos processos de escolha para atuarem nesta profissão como intérpretes. Pensando no atual contexto universitário brasileiro e na atual política educacional que defende a inclusão da pessoa com deficiência frequentando cursos superiores, e neste caso, estudantes surdos, cabe destacar que esta inclusão demanda a presença de um profissional para mediar as relações de comunicação entre surdos e ouvintes, favorecendo sua construção de conhecimento no espaço educacional. Entre os profissionais que atuam na efetivação de práticas de educação inclusiva encontram-se os TILS, o que é previsto pelo Decreto 5.626, responsável pela acessibilidade linguística dos alunos surdos que frequentam parte da Educação Básica e Ensino Superior, interpretando do Português para a LIBRAS e vice-versa. Conhecer melhor os caminhos e o perfil dos TILS e a sua atuação no ES, pode contribuir para a reflexão acerca das necessidades de formação deste profissional para atuar no processo de inclusão bilíngue de estudantes surdos em nível superior.
\end{abstract}

PALAVRAS-CHAVE: Educação Especial. Tradutor Intérprete de Língua Brasileira de Sinais. Ensino Superior. Inclusão Bilíngue

ABSTRACT: This article presents results from a broader study with LIBRAS- Brazilian Sign Language translators / interpreters (BSLIs) that work in Higher Education (HE). The study highlights the profile of professionals who work in higher education, demonstrating how varied are the contexts of different regions where they work, their ages, their educational background, how they became BSLIs, how they began their work at Institutions of Higher Education (IHE), among other factors. In this context, our main focus is on aspects of their training and current practice. The study is based on interviews and the results varied greatly, showing that there are different profiles and specificities in the processes by which they chose to work as interpreters. Considering the current Brazilian university context and education policies that defend inclusion of people with disabilities attending higher education courses, in this case, deaf students, it is important to point out that inclusion requires the presence of a professional to mediate communication relations between deaf and hearing people, in order to enable deaf people to construct knowledge in the educational environment. BSLIs are among the professionals working to implement practices of inclusive education; as established by the 5.626 Decree, they are the professionals responsible for the linguistic accessibility of deaf students from elementary education to higher education, interpreting Portuguese to LIBRAS and vice-versa. A better understanding of BSLIs' professional itineraries and profiles and their work on HE may contribute to reflecting about the requirements for preparing this professional in order for them to practice in bilingual inclusion processes of deaf students in Higher Education.

KEYWORDS: Special Education. Brazilian Sign Language Translator/Interpreter. Higher Education. Bilingual Inclusion.

1 Docente do Programa de Pós-graduação em Educação Especial da Universidade Federal de São Carlos. clacerda@ufscar.br/clacerda@uol.com.br

2 Fonoaudióloga e assessora do Programa de Educação Inclusiva Bilíngue junto à Secretaria Municipal de Educação de Campinas. tagurgel@hotmail.com 


\section{INTRODUÇÃo}

Estimativas do último censo demográfico (IBGE, 2000) indicam a existência de aproximadamente cinco milhões e 800 mil pessoas com surdez, segmento significativo da população que demandaria experiências linguísticas mediadas por uma língua de modalidade visual-espacial como é a Língua Brasileira de Sinais (Libras). A este número expressivo de pessoas com surdez não tem correspondido uma reação equivalente, consideradas as políticas linguísticas bilíngues oficiais e a destinação de recursos para consolidação dessas mesmas políticas, o que, consequentemente, se traduz na invisibilidade desse grupo (MOREIRA;FERNADES, 2008).

Dentre os profissionais que atuam para efetivar práticas de educação inclusiva voltadas às necessidades das pessoas com surdez destacamos os tradutores-intérpretes de língua de sinais (Libras/Português) (TILS), profissional previsto no Decreto 5.626, de dezembro de 2005 (BRASIL, 2005), responsável por dar acessibilidade linguística aos surdos que frequentam parte da Educação Básica (da segunda etapa do Ensino Fundamental em diante) e Ensino Superior (ES), interpretando do Português para a Língua de Sinais e vice-versa os conteúdos tratados no espaço educacional.

A figura do TILS não é nova nas experiências das comunidades surdas, contudo aparece apenas há uma década em documentos oficiais no Brasil, como profissional responsável pela acessibilidade de sujeitos surdos aos conteúdos tratados em espaços públicos e educacionais. Somente em 2005, com o referido decreto, esta figura profissional é descrita com detalhamento e atenção para exigências de formação especialmente para atuar nos espaços educacionais.

Apesar dos objetivos e estrutura afirmada no decreto, atravessamos um período de transição, em que a consolidação de projetos de educação bilíngue nos sistemas de ensino ainda é precária e os estudantes surdos que chegam ao ES, mais notadamente a partir da década de 1990 (impulsionados pelo reconhecimento legal de sua diferença linguística - Lei Federal 10.436) (BRASIL, 2002), apresentam especificidades, com sérias dificuldades relativas a seu letramento em Português, em geral. Tal fato se origina "nas escolhas ideológicas educacionais, tradicionalmente apoiadas na abordagem clínico-terapêutica fortemente marcadas pelo monolinguismo' (MOREIRA;FERNADES, 2008).

\section{O Tradutor-intérprete de Língua de Sinais}

O TILS é um profissional fundamental para mediar o acesso aos conhecimentos para estudantes surdos que frequentam o ensino regular. Assim, é crescente a demanda por este profissional, já que muitos surdos têm ingressado e/ou retornado à escola a cada ano sentindo-se acolhidos pela presença da Libras. 
Todavia, historicamente este profissional tem se constituído na informalidade, pela demanda dos próprios surdos, nas relações sociais, mediando a comunicação entre surdos e ouvintes. Os ambientes religiosos, por necessidade de propiciar acesso à doutrina à comunidade surda, favorecem a aprendizagem e desenvolvimento da fluência em Libras criando condições para que pessoas interessadas atuem como intérpretes mediando situações mais ou menos formais entre surdos e ouvintes. Deste modo, o intérprete se molda às demandas da prática e vai constituindo-se como TILS nas e pelas experiências vivenciadas.

É neste contexto que na década de 1990 surgem tentativas de dar uma formação específica para estes profissionais, principalmente por iniciativa da Federação Nacional de Educação e Instrução dos Surdos (FENEIS), que observando a heterogeneidade de desempenho dos intérpretes, propõe cursos de curta duração para formação. Estes cursos eram, em geral, ministrados por ouvintes e, ocasionalmente, por surdos e visavam ampliar os conhecimentos e fluência em Libras, sem outros focos de atenção. Além desta formação, nos últimos 20 anos foram realizados encontros regionais e/ou nacionais de intérpretes de Libras, com objetivo de troca de experiências e formação de aspectos pontuais relativos à atuação como intérprete (destacam-se discussões sobre ética e código de ética profissional) e, apenas em 2008, os TILS em todo o país organizaram-se em associações regionais criando em seguida uma federação nacional (FEBRAPILS) com representatividade junto ao World Association of Sign Language Interpretes - WASLI (órgão internacional que representa TILS do mundo todo).

A assunção da abordagem bilíngue para educação de surdos e seus desdobramentos político-pedagógicos é nova para todos que atuam na educação. A abordagem bilíngue passa a fazer parte das políticas educacionais brasileiras apenas recentemente, em função da pressão dos movimentos sociais, dos resultados de pesquisas nas áreas da Linguística e Educação e da incorporação de novos conhecimentos e tendências pelas agendas governamentais. No Brasil, o Decreto 5.626 (BRASIL, 2005), tornou obrigatória a presença deste profissional nos espaços educacionais que recebem alunos surdos. Na verdade, a Lei 10.098, de 2000, (BRASIL, 2000), orientada pela perspectiva da educação inclusiva, já previa a presença do TILS no nível superior, sem nenhuma descrição de como formá-lo. Deste modo, as instituições de ensino superior (IES) para atender às demandas judiciais ou da comunidade surda passaram a contratar pessoas que se dispunham a atuar como TILS sem atenção para uma avaliação pormenorizada de sua formação e competência para exercer esta função. Importava que atuassem em sala de aula de forma satisfatória do ponto de vista do aluno surdo e dos professores. Neste contexto, a entrada dos TILS na educação se deu sem um cuidado com sua formação prévia, e tornou-se comum pessoas sem formação no nível superior atuarem como intérpretes neste nível de ensino, ou ainda, não terem formação específica nas áreas de conhecimento em que atuavam. Ao mesmo tempo, o aluno surdo que chega ao ES muitas vezes tem domínio restrito da Libras e menor ainda do léxico da área de conhecimento específico na qual está estudando. Nem tudo 
que o intérprete traduz em Libras é acessível a ele, gerando problemas no espaço acadêmico. Além disso, as IES de modo geral estão pouco preparadas para a inclusão do aluno surdo e consequentemente para a presença do TILS em sala de aula. Na verdade, não se verifica a presença de um Projeto Político Pedagógico nas IES que contemple a inclusão de alunos surdos, para além da presença do intérprete em sala de aula (MARTINS, 2008).

Neste contexto, interessa-nos conhecer mais de perto o perfil daqueles que vêm atuando como TILS especificamente no ES, para que tomando como base este perfil possamos pensar ações de formação que colaborem para uma melhoria e aperfeiçoamento da atuação deste profissional e para a qualidade de ensino oferecida aos estudantes surdos.

\section{Desenvolvimento}

Este estudo trata da reflexão e análise de dados construídos a partir de 37 entrevistas realizadas com TILS que atuam no ES de instituições públicas ou privadas nas cinco regiões administrativas brasileiras, em diversos estados (Bahia, Espírito Santo, Goiás, Maranhão, Minas Gerais, Paraná, Pará, Rio de Janeiro, Rio Grande do Sul e São Paulo). As entrevistas foram realizadas usando ferramentas da internet. Inicialmente, alguns chats e listas de discussão de TILS foram frequentados, mantendo um diálogo informal com os participantes. Além destes, foram contatados TILS que conhecíamos de eventos científicos locais, regionais e nacionais e, ainda, indicação de amigos ou dos próprios intérpretes entrevistados. Nos contatos no ambiente virtual a pesquisa foi apresentada, feitos convites e requeridas autorizações e em seguida um roteiro de questões foi enviado a cada um dos participantes via e-mail ou MSN³ . O critério para participar do estudo foi então estar exercendo a função de TILS no ES no país e aceitar voluntariamente tomar parte no estudo. Nosso objetivo era conhecer as diferentes realidades de atuação e formação dos TILS no ES. Optamos por realizar entrevistas de forma virtual, usando ferramentas disponíveis na internet, visando contatar pessoas que atuassem em diferentes regiões do Brasil, com economia de recursos e agilidade. Destacamos que não se tratou da aplicação de um questionário, mas de perguntas guiadas por um roteiro que poderia ser ampliado pelos entrevistados. A forma de condução da entrevista virtual permitiu trocas e interação entre pesquisadores e intérpretes, com um intercâmbio de ir e vir de perguntas, respostas, comentários e esclarecimentos constituindo um espaço de diálogo, ainda que não presencial.

Foram enviadas 65 entrevistas e obtivemos resposta de 37 intérpretes. As entrevistas foram realizadas entre outubro de 2008 e agosto de 2009.

\footnotetext{
${ }^{3}$ MSN Web Messenger é um navegador da Web que permite que as pessoas conversem em tempo real e online, com amigos e parentes.
} 


\subsection{Perfil dos TILS que atuam no ES no País}

Entre os entrevistados 70\% são do sexo feminino e 30\% do sexo masculino. Segundo dados do Instituto Nacional de Estudos e Pesquisas Educacionais Anísio Teixeira (INEP, 2007), o número de mulheres atuando no ES tem aumentando a cada ano, além de elas serem a maioria na população do país. Em pesquisa recente Martins (2009), também encontrou um número predominante de TILS do sexo feminino atuando no ES, tendência presente em todos os segmentos da atuação profissional na área da educação.

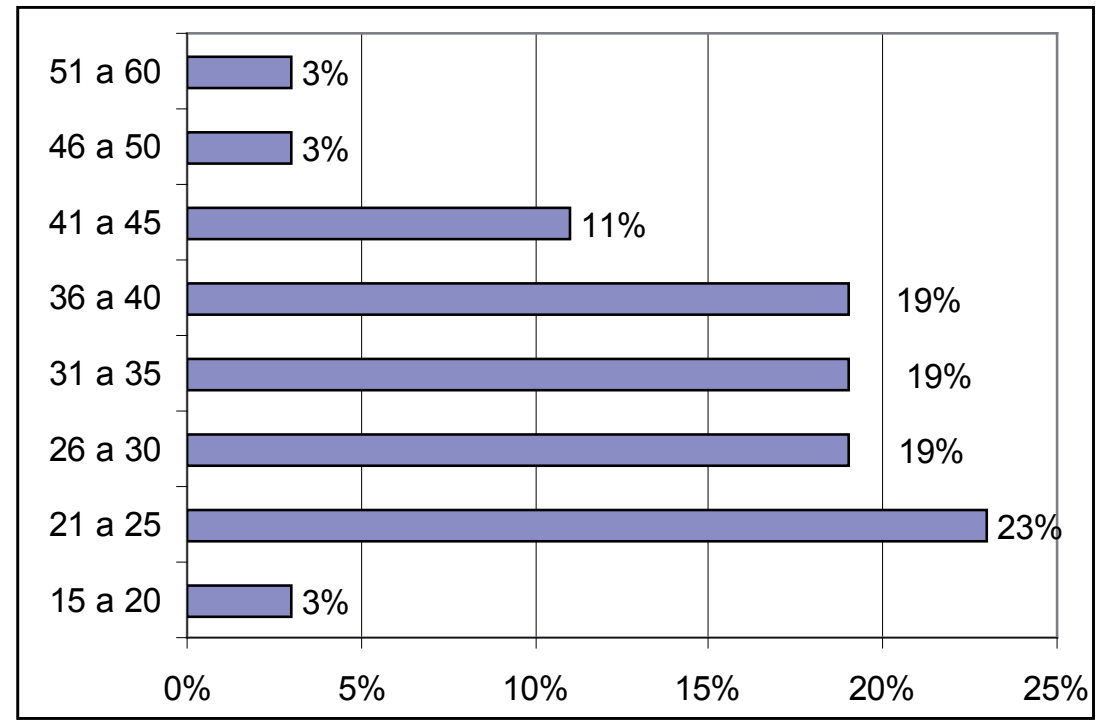

Gráfico 1 - Faixa etária dos entrevistados (anos)

Em relação à faixa etária, conforme aponta o Gráfico 1, temos que $61 \%$ dos TILS que atuam no ES têm entre 21 a 35 anos de idade, $30 \%$ entre 36 e 45 anos, $6 \%$ entre 46 a 60 anos e 3\% entre 15 a 20 anos de idade. Isso nos remete a um perfil de uma maioria de adultos jovens atuando no ES, com idade semelhante aos estudantes que frequentam este nível de ensino. A semelhança de faixa etária pode ser um fator que colabore para a aproximação dos alunos no que se refere às vivências e maturidade. 


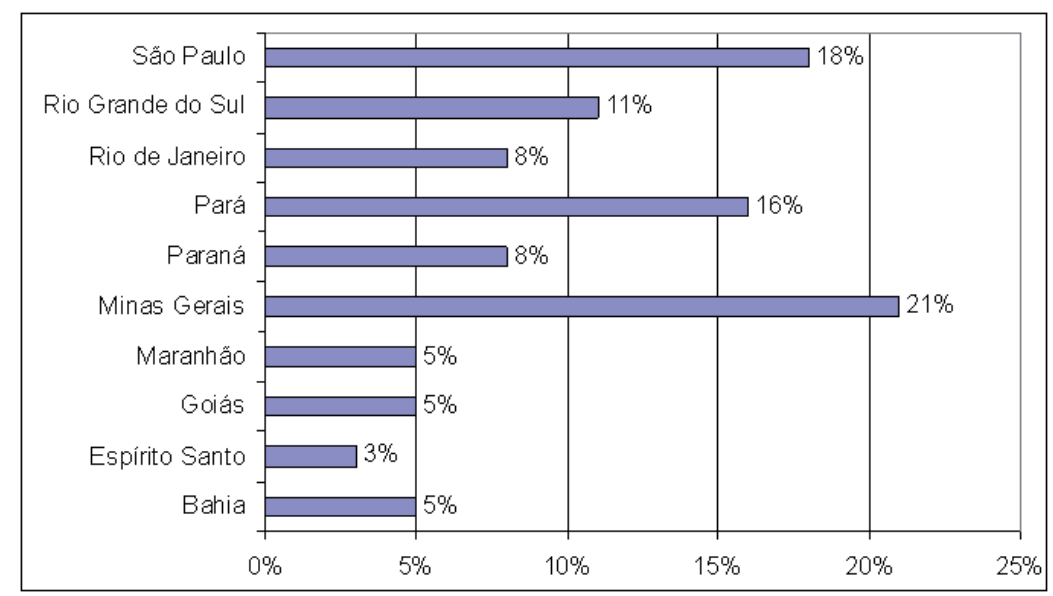

Gráfico 2 - Atuação por Estado da federação

O Gráfico 2 mostra que a participação de entrevistados dos estados de São Paulo e Minas Gerais foram as mais numerosas. Em função do modo como foram coletados os dados (participação espontânea) não podemos afirmar que, esta seja uma amostra fidedigna do que ocorre no país. Contudo, a maior adesão de intérpretes ao estudo foi dos que atuam nos estados que oferecem cursos para formação de intérpretes em nível superior há mais tempo (desde 2005). Talvez pelo interesse pela formação na área específica tenham tido maior interesse em participar da pesquisa. Cabe lembrar que, foram encaminhadas entrevistas para TILS que atuam em todas as regiões brasileiras, mas o maior retorno foi de intérpretes que atuam na região Sudeste, que é também a que concentra maior número de cursos oferecidos no nível superior no país e maior número de matriculas de alunos surdos segundo dados do censo do ES (INEP, 2007).

Em relação à situação administrativa das IES, em nossa pesquisa $70 \%$ dos entrevistados referiram atuar em instituições privadas, $13 \%$ em instituições públicas e $11 \%$ em ambas instituições. As instituições privadas representam quase $90 \%$ (INEP, 2007) das IES em nosso país. Assim, era esperado que a maior parte dos TILS atuassem neste tipo de instituição. Além disso, elas têm dado oportunidade e oferecido acolhimento aos alunos surdos, pois o ingresso destes nos processos seletivos ocorreu em maior número nos últimos anos, e nelas os surdos têm recebido frequentemente acompanhamento e apoio de profissionais intérpretes para ingresso e permanência no decorrer da formação acadêmica.

Deste modo, o investimento das instituições privadas em incluir estudantes surdos tem aumentado, seu processo seletivo é menos competitivo, o que favorece a entrada de um número maior de estudantes surdos e consequentemente de TILS.

Cabe lembrar que, a forma de contratação do TILS nestas instituições também é menos burocrática, pois depende apenas da própria IES, e quando esta 
não cumpre as exigências de acessibilidade previstas na legislação, o Ministério Público tem obrigado-as a atender com agilidade esta necessidade.

Já, no que diz respeito às IES públicas, o processo seletivo é bem mais competitivo, o ingresso de alunos surdos é restrito, pois, eles normalmente apresentam dificuldades no domínio do português em sua norma padrão. Em relação ao contrato dos TILS, as IES públicas dependem da criação de cargos por parte do legislativo federal, estadual e/ou municipal, fato que tem dificultado a presença deste profissional nestas IES. Muitos são contratados em vagas de substituição e ao final de um determinado período não podem ter seus contratos renovados por questões legais, gerando descontinuidade de atuação e de aproveitamento das capacidades adquiridas nas vivências junto ao ES.

No que se refere à formação em nível superior dos TILS entrevistados, $64 \%$ possui esta formação, em diferentes cursos. Todavia, os graduados não necessariamente têm formação na área na qual atuam, o que pode dificultar sua tarefa como intérpretes que, exige agilidade linguística e conhecimento específico sobre os conteúdos tratados (NAPIER, 2002). Além disso, temos que 23\% dos entrevistados estão cursando o ES, colocando-se em situação de experiência educacional muito semelhante aos estudantes surdos que atendem. Destaca-se ainda que, dos entrevistados $13 \%$ não têm experiência no ES, ou seja, se deparam com a realidade acadêmica apenas quando iniciam suas atividades enquanto TILS, sem uma reflexão e conhecimento mínimos sobre este nível educacional.

Ainda sobre a formação em nível superior, muitos dos que têm graduação concluída também frequentam/frequentaram cursos de aperfeiçoamento, especialização e mestrado indicando interesse em sua formação continuada, em geral voltada para formação em Libras e/ou atuação como intérprete. Assim, percebemos uma configuração bastante heterogênea em relação à formação das pessoas que atuam como TILS no ES.

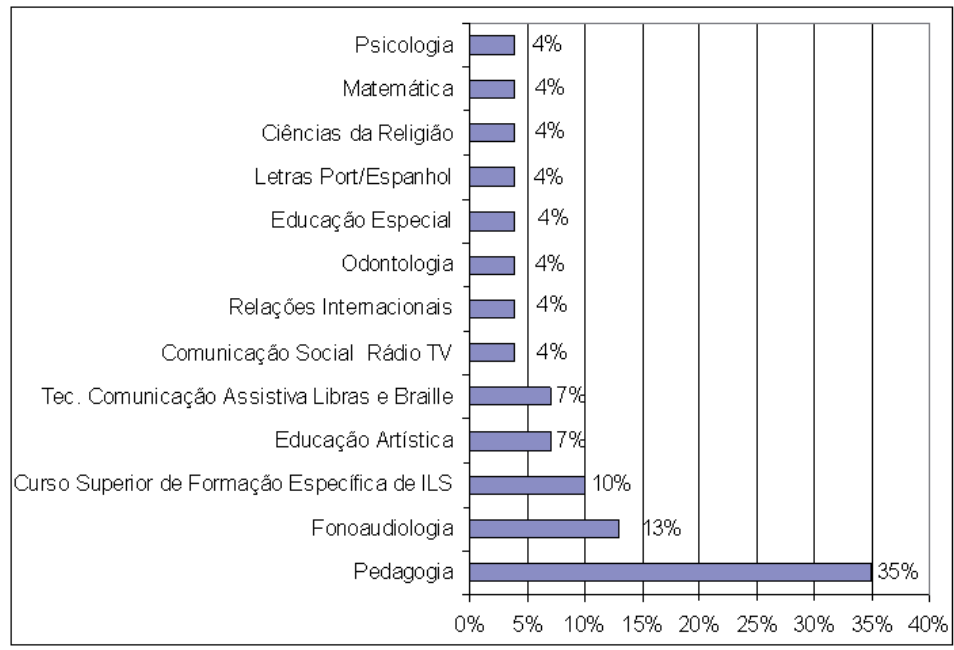

Gráfico 3 - Formação em curso superior 
No gráfico 3, podemos observar que 35\% dos entrevistados tem formação em Pedagogia, 13\% em Fonoaudiologia e 4\% em Educação Especial, num total de $52 \%$ dos entrevistados. Isso nos remete pensar que, como essas áreas tratam durante a formação de aspectos relativos às pessoas com necessidades especiais, normalmente com disciplinas ou estágios na área da surdez, favorecem o aprendizado e a experiência nas questões sobre os surdos e, podem ter colaborado para o interesse e experiência com Libras, além do conhecimento sobre a necessidade e função do TILS, e de alguma maneira, contribuído para esta escolha profissional. Além disso, 10\% dos entrevistados frequentaram cursos de formação específica para TILS ${ }^{4}$ oferecidos por IES privadas, com início anterior ao Decreto 5.626 (BRASIL, 2005)

Destacamos que, apesar dos cursos para TILS serem poucos, em nosso estudo, encontramos uma parcela de profissionais com investimento nesta formação específica. Os demais entrevistados, excetuando-se aqueles com formação em Letras, se graduaram em diversas áreas do conhecimento que não focalizam aspectos educacionais, relacionados à prática do trabalho com interpretação e línguas, ou temáticas voltadas para pessoas surdas e suas características. Nesta direção, podemos inferir que a formação no ES, contribui para o seu conhecimento sobre características de funcionamento deste nível de ensino, mas não para sua atuação como TILS. Enfatiza-se ainda, que das entrevistas, é possível depreender que a maior parte dos intérpretes formados em áreas não afins com sua atuação, frequentemente é filho de pais surdos, ou tem algum parente ou amigo surdo e que, devido a esse contato estreito com a comunidade surda, aprendeu a Libras e passou a atuar como TILS, paralelamente à formação acadêmica recebida (eles representam quase um terço dos entrevistados).

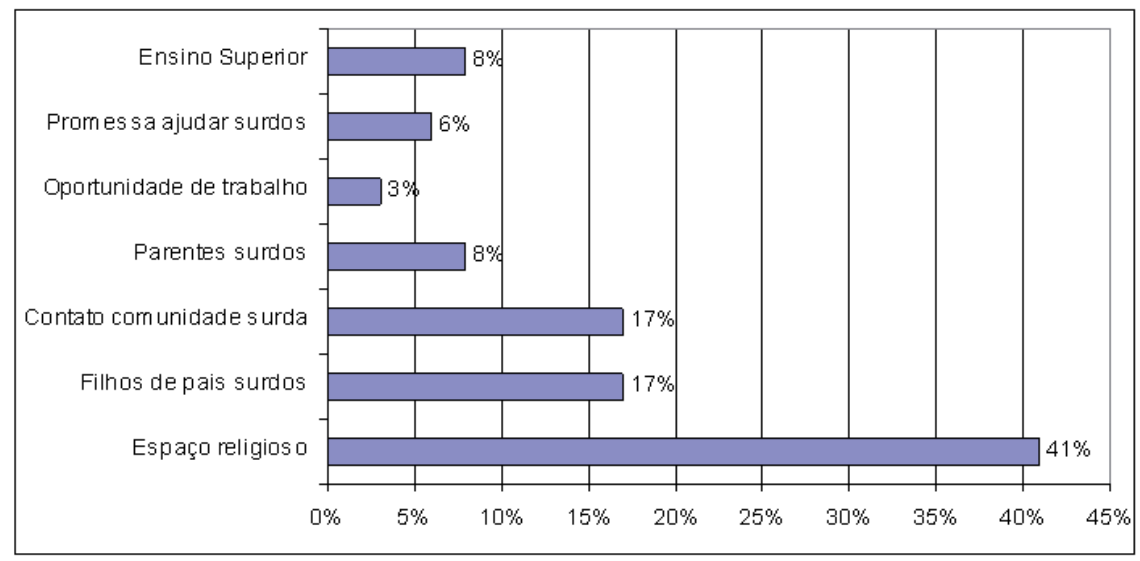

\section{Gráfico 4 - Como você começou ou se tornou TILS}

\footnotetext{
4 Os cursos Tecnólogos (Libras e Braille) e Sequencial de Formação específica para Intérpretes de Libras são cursos em nível superior para formação de TILS que surgem em 2005 em IES privadas. Em 2008, é criado o curso de Bacharelado em Letras/Libras - Universidade Federal de Santa Catarina (UFSC), organizado na modalidade a distância, oferecido em diversos pólos em todo o país para formação de TILS. Em 2009, uma primeira turma presencial do bacharelado Letras/Libras é criada pela UFSC.
} 
Em relação ao início da atuação como TILS, dos entrevistados $41 \%$ refere ter se tornado intérprete pelo contato com surdos (familiares e ou comunidade surda) dentro de espaços religiosos. Tal achado corrobora dados da literatura que indicam que muitos intérpretes se formaram no espaço religioso que cumpre papel de destaque e marca modos de ação dos TILS (ROSA, 2006). Nas religiões, um foco privilegiado é trazer mais adeptos para a crença ou fé professada, além do aspecto caridoso e de cuidados. É nesse contexto que, muitos dos entrevistados se tornaram intérpretes, e nesta perspectiva pode-se inferir que, esta abordagem se manifeste em seus modos de constituição e que, a idéia de ajuda e caridade, estejam presentes, por vezes, no cenário acadêmico.

Já $17 \%$ dos entrevistados, aprenderam Libras e se tornaram TILS por serem filhos de pais surdos. Outros $17 \%$ são intérpretes que tiveram contato com a comunidade surda, através de laços de amizade, e $8 \%$ os que têm algum parente surdo, ou seja, provavelmente foram se tornando TILS na informalidade das demandas sociais e cotidianas. Assim, entre os entrevistados apenas uma minoria se tornou intérprete por interesse profissional e pela oportunidade de trabalho.

Tabela 1- Curso ou formação específica em Libras

\begin{tabular}{lc}
\hline Curso ou formação específica em Libras & $\%$ \\
\hline Associações de Surdos & $40 \%$ \\
Extensão Universitária & $21 \%$ \\
Outros cursos Privados & $12 \%$ \\
Instituições Religiosas & $10 \%$ \\
Financiados com verba Pública & $7 \%$ \\
Formação em IES - nível superior & $5 \%$ \\
Não fez formação específica em Libras & $5 \%$ \\
\hline
\end{tabular}

$\mathrm{Na}$ Tabela 1 apresentamos os tipos de cursos de Libras frequentados pelos TILS. Podemos observar que $40 \%$ dos intérpretes fizeram algum curso ou capacitação em língua de sinais promovido por associações de surdos, eles referem cursos modulares oferecidos com formação em Libras do nível básico ao nível avançado. Apenas $26 \%$ dos entrevistados frequentaram disciplinas de Libras em universidades, em cursos extensão ou de formação específica. Alguns referiram frequentar cursos dentro de oficinas em instituições religiosas e $5 \%$ dos entrevistados não frequentaram nenhum tipo de curso de Libras. A procura por cursos que oferecem formação em língua de sinais, quando comparada à procura por formação específica para atuar como TILS, como veremos mais adiante, foi muito maior, confirmando afirmações (dos entrevistados) que defendem que, 
o fundamental para a prática de interpretação é o aprendizado da língua, sem atentar para a necessidade de formação específica para atuar como TILS.

Em relação à duração (número de horas) dos cursos de Libras, 42\% dos entrevistados que frequentaram cursos de Libras o fizeram em cursos com menos de 100 horas, 19\% em cursos com duração entre 121 e 250 horas e 39\% em cursos com duração entre 251 e 540 horas. Gostaríamos de destacar o fato de que a maioria dos que frequentaram cursos com menos de 100 horas, são aqueles provenientes de famílias de pessoas surdas. Enfatiza-se que o contato com a comunidade surda e o uso da língua, não necessariamente gera reflexões sobre seus aspectos gramaticais ou linguísticos necessários a atuação como TILS. Isso não quer dizer que cursos mais longos sejam suficientes e adequados à formação, mas talvez possibilitem uma reflexão maior sobre as características da língua que se faz necessária e importante para o trabalho do TILS.

Pelos dados obtidos nas entrevistas soubemos que a maioria dos entrevistados (57\%) não frequentou nenhum curso de formação específica na área de tradução e interpretação em Libras. Este dado é alarmante, pois atuam como intérpretes segundo suas próprias convicções sem terem realizado qualquer formação para tal.

Tabela 2 - Cursos de formação específica para TILS

\begin{tabular}{lc}
\hline \multicolumn{1}{c}{ Formação } & $\%$ \\
\hline Sem formação específica & $55 \%$ \\
Aperfeiçoamento e capacitação pela FENEIS & $18 \%$ \\
Formação em IES - nível superior & $11 \%$ \\
Associações de Surdos & $7 \%$ \\
Oficinas em instituições religiosas & $6 \%$ \\
Especialização & $3 \%$ \\
\hline
\end{tabular}

Na Tabela 2 podemos conhecer os cursos frequentados pelos $45 \%$ de intérpretes que estão fazendo ou fizeram algum tipo de formação específica. Do total de entrevistados $11 \%$ estão cursando e/ou cursaram formação em nível superior, indicando que apenas um pequeno grupo passou por formação mais completa e com maior reflexão. A maior parte do grupo fez cursos de formação junto à FENEIS (18\%), 7\% fizeram cursos em outras associações de surdos, $6 \%$ frequentou oficinas oferecidas por instituições religiosas, e apenas 3\% fizeram especialização na área de TILS.

Infelizmente, a procura para aperfeiçoar os conhecimentos e formação na profissão ainda é pequena. As entrevistas revelam que muitos não se incomodam com tal fato, e entendem que a prática é suficiente para a qualidade de sua atuação. 
Como em qualquer profissão, seria fundamental manter uma formação continuada, atentos a seu aperfeiçoamento, conhecimento de novas técnicas, ampliação do conhecimento linguístico e de experiências mais sistematizadas que cursos de formação podem favorecer.

Também perguntamos para aqueles que fizeram algum tipo de formação como TILS sobre a duração dos cursos realizados. Dos entrevistados, 14\% fizeram cursos com duração entre 20 a 80 horas. São cursos breves que não permitem aprofundamento maior nas diversas áreas que envolvem a formação do TILS. Os $11 \%$ que cursaram formação em nível superior fizeram cursos com mais de 540 horas, indicando maior investimento em sua formação. Outros 11\% informaram formação entre 81 e 230 horas e 9\% entre 231 e 540 horas. Ainda que não tenham sido averiguadas outras características desta formação, o número de horas parece indicar uma abordagem mais aprofundada, revelando preocupação maior com a formação.

Em relação ao ano em que frequentaram cursos de formação para atuarem como TILS, um terço respondeu que a formação se deu entre 1989 e 1999 - capacitação realizada há mais de uma década, sem atualizações mais recentes. Os demais realizaram sua formação no período entre 2000 a 2008, indicando interesse em formação em consonância com o aumento da procura por este profissional pelas IES.

Em relação aos TILS que foram certificados pelo Prolibras $^{5}$ encontramos que entre os 37 entrevistados, 68\% têm essa certificação e 32\% não. Destaca-se que, a maioria dos entrevistados está de posse da certificação prevista pela legislação (Decreto 5626/2005) (BRASIL, 2005) ainda que o exame tenha sido implantado em 2007. A busca pela certificação é um reconhecimento público de que a pessoa tem condições básicas para atuar na área de tradução-interpretação de Libras e vem sendo paulatinamente exigida pelas IES e em concursos públicos. As entrevistas mostram ser maior o número de entrevistados com certificação no Prolibras (68\%) que aquele com formação específica para atuarem como TILS (45\%). Como as exigências legais remetem à certificação e não à formação específica os resultados encontrados apenas confirmam a tendência de interesse pela certificação induzida pela própria legislação vigente.

Sobre como os intérpretes iniciaram sua atuação no ES, houve processo seletivo ou alguma forma de avaliação por parte da IES para 39\% deles, para outros $45 \%$ o início do trabalho se deu por indicação de amigos surdos ou por pessoas que já atuavam nesse espaço. Em muitos casos, os intérpretes relataram atuar anteriormente em empresas ou outros contextos sociais com ou sem nenhum envolvimento com a educação, e foram indicados para as IES por pessoas que

5 Exame Nacional de Proficiência em Língua Brasileira de Sinais (Prolibras). Promovido pelo Ministério da Educação certifica pessoas proficientes em Libras, para atuarem como professores, instrutores ou tradutores/ intérpretes de Libras em nível médio e/ou superior. 
já conheciam seu trabalho. Apenas um entrevistado iniciou sua atividade por concurso público.

Em relação às exigências para atuarem nas IES, as respostas foram diversificadas. Dos entrevistados 16\% referiram que nenhuma exigência além do conhecimento de Libras foi requerida. Não responderam a esta pergunta $11 \%$. Os demais referiram situações de exigência variadas: para $8 \%$ apenas a certificação no Prolibras foi exigida, para $19 \%$ apenas a formação em nível superior, e para aproximadamente um terço dos entrevistados foram solicitadas formação em nível superior (concluído e/ ou em andamento) e certificação no Prolibras. Além disso, os demais entrevistados informaram exigências tais como: formação ou conhecimento na área da educação/ pedagógica; experiência como educador, indicação de outros profissionais, capacitação para atuar como intérprete entre outras solicitações. Neste sentido, encontramos um perfil diversificado de requisitos propostos pelas IES, permitindo que muitos dos entrevistados atuem sem nenhuma certificação e/ ou exigência de formação e experiência.

Os modos como os TILS referem terem sido escolhidos e as exigências feitas revelam um interesse maior ou menor das IES em buscar profissionais competentes para exercerem a função. As respostas indicam que algumas instituições se preocupam apenas em colocar alguém para atuar, sem atentar para a qualidade deste profissional, sua formação ou certificação, aceitando indicações, sem preocupação e avaliação da competência desta pessoa para sua função.

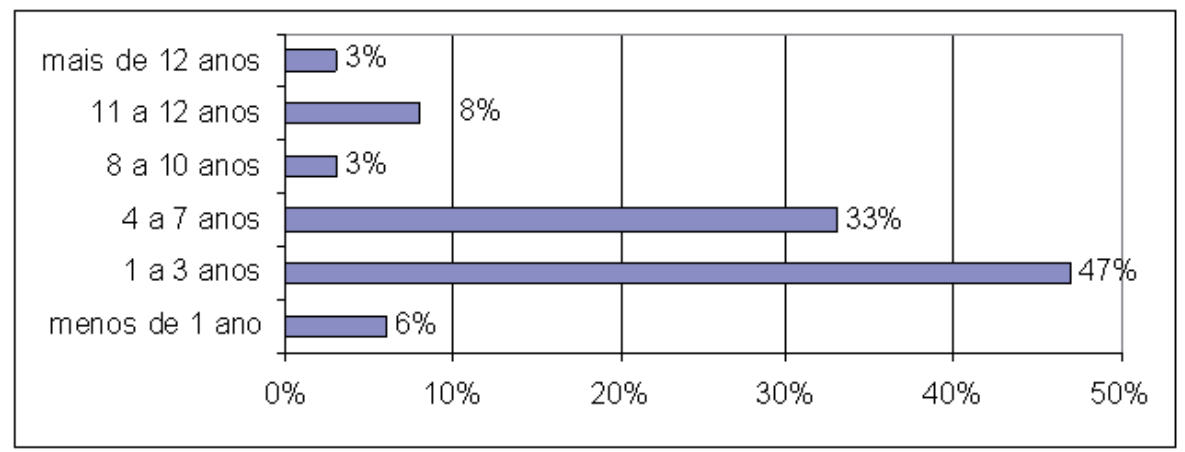

Gráfico 5 - Há quanto tempo trabalha na IES como TILS

Em relação ao tempo de atuação dos TILS nas IES, no gráfico 5 temos que $86 \%$ dos intérpretes atuam nesta função entre menos de um ano a sete anos. Ou seja, atuação recente, iniciada já no século XXI, apontando para a abertura de campo e de espaço de trabalho na medida em que as políticas de inclusão educacional foram sendo implantadas. Assim, temos um número maior de sujeitos surdos chegando ao ES com seu direito de acessibilidade linguística reconhecido. No que diz respeito à forma de contrato de trabalho dos TILS nas IES, a maioria respondeu 
que é através de contrato CLT ${ }^{6}$. Isso demonstra que existe por parte das instituições, interesse e preocupação em contratarem intérpretes como funcionários, legalmente registrados, com os benefícios e direitos legais. Todavia, as formas de contratação ainda são plurais, pois alguns intérpretes são contratados como professores (de Libras entre outros), provavelmente pela não existência desta função nos quadros das IES, ou ainda por uma dificuldade de definição deste papel profissional. Contrato de experiência sem data foi relatado por $10 \%$ dos entrevistados e como autônomo por outros $10 \%$. A lei trabalhista prevê contrato por tempo determinado justamente para avaliação de ambas as partes sobre o interesse pela continuidade no posto de trabalho. Cabe lembrar que, esse tipo de contrato apresenta duração e prorrogação por tempo limitado, e que para a manutenção do profissional, transcorrido o prazo determinado pela lei, ele deve ser registrado ou deixar o trabalho. Nesse sentido, é necessário investigar se algumas IES estão usando deste expediente para manter funcionários o máximo possível sem registro definitivo, mandando-os embora e contratando novos profissionais (para economia de recursos) criando assim, um rodízio de profissionais nada benéfico ao andamento do trabalho acadêmico.

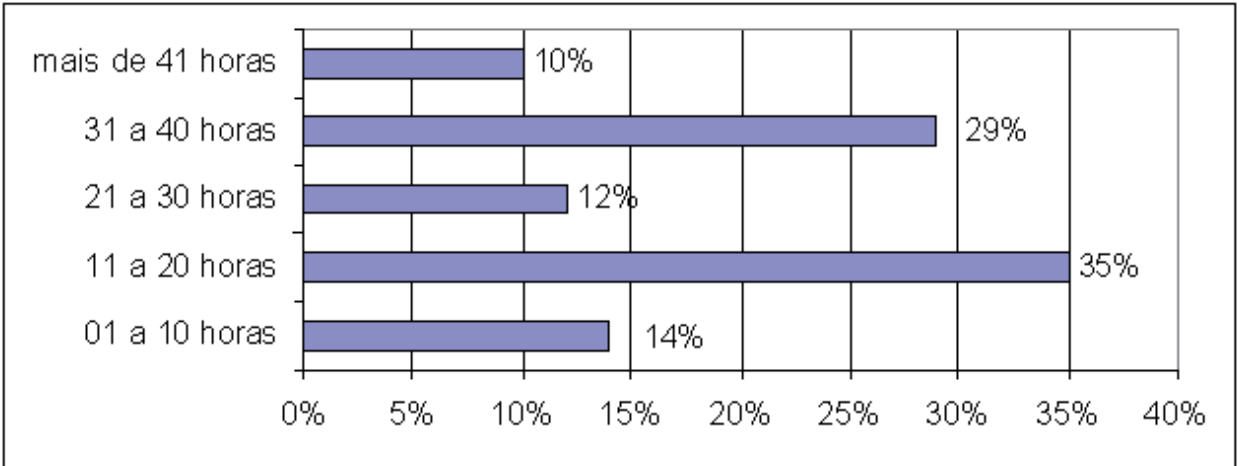

Gráfico 6 - Carga horária semanal como TILS

No gráfico 6, temos que 35\% dos TILS trabalham num período de 11 a 20 horas semanais. Apesar do cansaço físico, essa carga horária é muito comum nas instituições e seria compatível com períodos de atuação e descanso ao longo da semana. Contudo, temos $29 \%$ dos intérpretes atuando mais de 31 horas semanais, em um trabalho exaustivo, principalmente porque muitos deles referem atuar em mais de uma instituição, interpretando frequentemente temas bastante distintos.

As entrevistas revelam também que a maioria deles não conta com a ajuda de outros intérpretes para substituí-los em caso de ausência ou por sobrecarga de trabalho. É comum que códigos de ética ou manuais que orientam a atuação dos TILS (MARTINS, 2009) indiquem que a cada 20 ou 30 minutos o intérprete descanse pelo menos 10 minutos. Essa é uma regra comum para intérpretes de

${ }^{6}$ Consolidação das Leis do Trabalho. Contrato individual de trabalho regulado pela legislação vigente. 
línguas orais que atuam em conferências e outros tipos de eventos, mas nada observada quando se trata da atuação de TILS no espaço educacional. Isso se deve ao fato de as contratações ainda serem escassas por parte das IES e não ser previsto qualquer período de descanso específico para estes profissionais. Dessa maneira, muitos deles manifestam estresse, dores musculares e sofrem muita cobrança não só por parte das instituições, mas também por parte dos alunos surdos com relação a seu desempenho no trabalho.

Além disso, muitos referiram atuarem em diferentes cursos, em diferentes áreas do conhecimento e períodos, sendo bastante exigidos. Com isso, além da habilidade com cada uma das línguas envolvidas, precisariam estar constantemente atualizados em relação ao conhecimento específico dos temas abordados, com leituras e aprofundamento que nem sempre ocorrem e que convergem para prejuízos nos resultados da interpretação.

Os entrevistados informaram atuarem em diversos cursos de graduação: Pedagogia, Administração, Letras, Arquitetura, Letras/Libras, Direito, Teologia, Teatro, Moda, Geografia, Integração no mercado de trabalho, Etiqueta, Estética e Imagem Pessoal, Ciências Sociais, Turismo, Arte Cênica, Relações Internacionais, Ciências Contábeis, Engenharia de Controle e Automação, Desenho industrial, Tecnologia de Mídias Digitais, Informática, Sistemas de Informação, Educação Física, Fisioterapia e Agroecologia. Destes a concentração mais significativa está no curso de Pedagogia, área de atuação de $24 \%$ dos entrevistados.

Sobre os desafios impostos por esta nova profissão, os entrevistados referiram a falta de regulamentação da profissão, a necessidade constante de aprimoramento e conhecimento em Libras e a necessidade de uma formação continuada como os principais elementos.

Muitos entrevistados criticaram aqueles que atuam sem conhecimento mínimo sobre técnicas de interpretação ou investimento em formação. Sua atuação pode prejudicar a imagem profissional e, principalmente, os estudantes surdos que dependem de sua mediação no espaço acadêmico.

\section{Algumas considerações}

Os dados encontrados indicam um perfil amplo dos intérpretes e não foi possível identificar características regionais para além da questão da formação específica oferecida apenas em estados da região sudeste. Porém, é possível destacar que a maioria deles passou por algum tipo de formação em Libras, mas menos da metade fez formação específica para atuar como TILS, e neste grupo um terço fez esta formação há mais de dez anos indicando pouco interesse por formação continuada para a área de atuação. O movimento da maioria é ter a certificação pelo Prolibras cumprindo as exigências legais. Podemos dizer que a necessidade recente dessa figura no âmbito acadêmico ainda está em processo de reconhecimento e desenvolvimento e que as próprias IES precisam definir 
com maior clareza o perfil de profissional que interessa às necessidades de seus estudantes surdos.

Lacerda (2002), Harrison e Nakasato (2004) e Martins (2008), entre outros autores, discutem a importância de se ter uma formação de qualidade para atuar como TILS, além do conhecimento linguístico aprofundado tanto em Libras como em Português. O contato com a comunidade surda é fundamental, mas a interpretação requerer conhecimentos de mundo, escolhas lexicais e de sentido que precisam ser trabalhadas para que o intérprete atue adequadamente favorecendo a aprendizagem do estudante surdo.

Os depoimentos oriundos de realidades de diferentes regiões do Brasil nos ajudam a visualizar a área em constituição e apontam para características que podem ser consideradas nas reflexões e projetos que se interessam pelas necessidades formativas de TILS e mais especificamente para a formação de futuros intérpretes educacionais.

\section{REFERENCIAS}

BRASIL. Lei n ${ }^{0}$ 10.436, de 24 de abril de 2002. Dispõe sobre a Língua Brasileira de Sinais (Libras) e dá outras providências. Diário Oficial da União, Brasília, 24 de abril, 2002.

. Decreto $n^{0} 5.626$, de 22 de dezembro de 2005. Regulamenta a Lei $n^{\circ} 10.436$, de 24 de abril de 2002, que dispõe sobre a Língua Brasileira de Sinais (Libras), e o art. 18 da Lei $\mathrm{n}^{\mathrm{o}}$ 10.098, de 19 de dezembro de 2000. Diário Oficial da União, Brasília, 22 de dezembro, 2005.

HARRISON, M.P.; NAKASATO, R. Educação universitária: reflexões sobre uma inclusão possível. In: LODI, A.C.B. et al. Letramento e Minorias. Porto Alegre, 2004.

IBGE. Instituto Brasileiro de Estatística e Geografia. Censo 2000. Disponível em: <http:/ / www.ibge.gov.br/censo/>. acesso em: 10 jul .2009.

INEP. Resumo Técnico do Censo de 2007. Disponível em: <http:/ /www.inep.gov.br/ download/superior/censo/2007/Resumo_tecnico_2007.pdf>. Acesso em: 20 out. 2009.

LACERDA, C.B.F. O intérprete Educacional de língua de sinais no Ensino Fundamental: refletindo sobre limites e possibilidades. In: LODI, A.C.B et al. Letramento e Minorias. Porto Alegre, p.120-128, 2002.

MARTINS, D. A. Trajetórias de formação e condições de trabalho do intérprete de libras em instituições de Educação Superior. 2009. 135f. Dissertação (Mestrado em Educação) Pontifícia Universidade Católica de Campinas, Campinas, 2009.

MARTINS, V. R. O. Educação de Surdos no Paradoxo da Inclusão com Intérprete de Língua de Sinais: Relações de poder e (re) criações do sujeito. 2008. 140f. Dissertação (Mestrado em Educação) - Pontificia Universidade Católica de Campinas, Campinas, 2008. 
MOREIRA, L. C.; FERNANDES, S. Acesso e permanência de estudantes surdos no Ensino Superior. In: SEMINÁRIOS DE INSTITUIÇÕES DE ENSINO SUPERIOR: TRAJETÓRIA DO ESTUDANTE SURDO, 1., 2008, Londrina. Anais...Ed. UEL. Londrina,PR.

Disponívelem<http://www.uel.br/eventos/seminariosurdez/pages/propostas.php>. Acesso em: 1 jul.2009.

NAPIER, J. University interpreting: linguistic issues for consideration. Journal of deaf Studies and deaf Education, Parramatta, p. 280-301, Fall, 2002.

ROSA, A. S. Entre a visibilidade da tradução da lingua de sinais e a (in) visibilidade da tarefa do intérprete. In: ENCONTRO DOS PROFISSIONAIS TRADUTORES/ILS DE MS-CAMPO GRANDE, 2., 2006. Campo Grande. Anais... EPILMS:Uniderp, p.23-45, 2006.

Recebido em: 25/03/2011

Reformulado em: 18/07/2011

Aprovado em: 14/10/2011 